\title{
DAKTILITAS
}

Jurnal Teknik Sipil Universitas Tulungagung

Journal Home Page : https://journal.unita.ac.id/index.php/daktilitas

Volume 1, Nomor 1, Tahun 2021

\section{OPTIMALISASI DAN KOMBINASI ALAT BERAT \\ PADA PEKERJAAN GALIAN TANAH \\ (Studi Kasus: Proyek Pembangunan Dealer Honda Pasific, Kab. Tulungagung)}

\author{
OPTIMIZING THE USE OF HEAVY EQUIPMENT ON THE WORK \\ OF THE SOIL EXCAVATION \\ (Case Study: Honda Pasific Dealer Development Project, Kab. Tulungagung)
}

\author{
Danang Wijanarko, S.T,.M.T \\ Program Studi Teknik Sipil Universitas Tulungagung \\ Jalan Kimangunsarkoro Beji, Kec. Boyolangu, Kab. Tulungagung 66233 \\ Alamat korespondensi : \\ email: danangwnjrk11@gmail.com
}

\begin{abstract}
Abstrak: In the development project "Dealer Honda Pacific Kab. Tulungagung", which has a rice field contour, requires a cut and fill job using heavy equipment to level the soil surface. The data analysis method used an analytical description consisting of data collection techniques, data analysis, implementation techniques and results. After necessary data has been collected, planning for the use of each tool with different tool capacities is made and 4 combinations of tools are made. From each combination, productivity and equipment rental costs for the use of heavy equipment will be calculated. Based on the results, the combination IV is obtained where the combination IV uses 1 units 1,2 m3 excavators, 3 dump trucks with a capacity of $8 \mathrm{~m} 3$ and $3 \mathrm{D} 3 \mathrm{G}$ bulldozers. The processing time required is 34 days for the use of excavators and dump trucks and the use of bulldozers it takes 48 days to work and the total cost is Rp.600,920,000,--
\end{abstract}

Keywords: excavators, dump trucks, bulldozers, capacity, productivity.

\begin{abstract}
Abstrak
Abstrak: Pada proyek pembangunan “Dealer Honda Pasific Kab. Tulungagung”, yang memiliki kontur tanah persawahan diperlukan adanya pekerjaan cut and fill menggunakan alat berat untuk meratakan permukaan tanahnya. Metode analisis data yang digunakan adalah deskripsi analitis yang terdiri dari teknik pengumpulan data, analisa data, teknik pelaksanaan dan hasil. Setelah data- data yang diperlukan terkumpul kemudian dilakukan perencanaan penggunaan dari masing-masing alat dengan kapasitas alat yang berbeda dan dibuatkan 4 buah kombinasi alatnya. Dari masing-masing kombinasi akan dihitung produktifitas dan biaya sewa alat untuk penggunaan alat berat tersebut. Berdasarkan hasil perhitungan yang telah dilakukan, maka diperoleh kombinasi IV Dimana kombinasi IV menggunakan 1 unit excavator $1,2 \mathrm{~m}^{3}, 3$ unit dump truck berkapasitas $8 \mathrm{~m}^{3}$ dan 3 unit bulldozer D3G. Waktu pengerjaan yang diperlukan adalah 34 hari untuk penggunaan excavator dan dump truck dan untuk penggunaan bulldozer diperlukan waktu pengerjaan selama 48 hari dan total biaya yang dikeluarkan sebesar Rp.600.920.000,-.
\end{abstract}

Kata kunci: excavator; dump truk; bulldozer; kapasitas; produktivitas;

\section{PENDAHULUAN}

Pada umumnya setiap pekerjaan pembangunan dalam bidang konstruksi selalu berkaitan dengan masalah tanah. Dimana proyek pembangunan "Dealer Honda Pasific Kab. Tulungagung" yang memiliki Iuas pembangunan $6.400 \mathrm{~m}^{2}$ dan Iokasi daerah tersebut berupa daerah persawahan, maka perlu dilakukan pekerjaan cut and fill untuk meratakan permukaan tanahnya. Untuk mempermudah dan mempercepat pekerjaan tersebut digunakan alat berat seperti excavator, dump truck dan bulldozer. 
Dalam pelaksanaanya penggunaan alat berat pada proyek tersebut dinilai kurang optimal, karena kapasitas dan jumlah alat yang digunakan tidak sesuai dengan kondisi medan di lapangan dan banyaknya volume pekerjaan yang akan dikerjakan. Penggunaan alat berat yang kurang tepat dengan kondisi dan situasi lapangan pekerjaan akan berpengaruh pada rendahnya produksifitas alat dan tidak tercapainya jadwal atau target yang telah ditentukan. Selain itu semakin lama pengunanan alat yang digunakan semakin besar juga biaya yang harus dikeluarkan. Sehingga penulis melakukan penelitian untuk menganalisa kapasitas dan jumlah kebutuhan alat berat pada proyek pembangunan "Dealer Honda Pasific Kab. Tulungagung", agar didapat hasil yang optimal dalam pekerjaan cut and fill tersebut.

\section{TINJAUAN PUSTAKA}

\section{Alat Berat}

Alat-alat berat yang sering dikenal di dalam ilmu Teknik Sipil merupakan alat yang digunakan untuk membantu manusia dalam melakukan pekerjaan pembangunan suatu struktur bangunan. Alat berat merupakan faktor penting di dalam proyek, terutama proyekproyek konstruksi maupun pertambangan dan kegiatan Iainnya dengan skala yang besar. Tujuan dari penggunaan alat-alat berat tersebut adalah untuk memudahkan manusia dalam mengerjakan pekerjaannya, sehingga hasil yang diharapkan dapat tercapai dengan lebih mudah dengan waktu yang relatif lebih singkat (Rochmanhadi, 1985)

\section{Excavator}

Excavator atau sering disebut dengan Backhoe termasuk dalam alat penggali hidrolis memiliki bucket yang dipasangkan di depannya. Alat penggeraknya traktor dengan roda ban atau crawler. Backhoe bekerja dengan cara menggerakkan bucket ke arah bawah dan kemudian menariknya menuju badan alat.

\section{Dump Truck}

Seperti yang telah diketahui bahwa dump truk sangat efisien untuk pengangkutan jarak jauh. Namun, alat ini juga memiliki kekurangan dibanding alat lain karena dump truk memerlukan alat Iain untuk pemuatan. Dalam pemilihan ukuran dan konfigurasi truk ada beberapa faktor yang mempengaruhi, yaitu material yang akan diangkut dan excavator atau Ioader pemuat.

\section{Bulldozer}

Bulldozer merupakan traktor yang dipasangkan pada blade dibagian depannya. Blade berfungsi untuk mendorong atau memotong material yang ada didepannya. Jenis pekerjaan yang biasanya menggunakan dozer atau bulldozer adalah Mengupas tanah bagian atas dan pembersihan Iahan dari pepohonan, Pembukaan jalan baru, Pemindahan material pada scraper, menyebarkan material dan mengisi kembali saluran.

\section{Faktor - Faktor yang Mempengaruhi Produksi Alat}

Kemampuan alat dalam manghasilkan produksi sangat dipengaruhi oleh berbagai faktor. Ketelitian dalam menentukan faktor - faktor yang mempengaruhi kemampuan produksi alat akan memberikan nilai atas faktor-faktor tersebut. Diantaranya yakni akan menghasilkan ketepatan perhitungan produksi peralatan sekaligus memberikan ketepatan waktu penyelesaian dan ketepatan biaya produksi . Berikut merupakan faktor-faktor tersebut:

1. Faktor Kondisi Peralatan

2. Faktor kondisi Medan dan faktor Material

3. Faktor Manajemen

4. Koefisien Traksi

5. Faktor Cuaca 

6. Job Faktor
7. Pengaruh Kelandaian ( Grade Resisten)
8. Pengaruh ketinggian (Altitude)

\section{Waktu Siklus}

Waktu siklus adalah waktu muat yang dibutuhkan alat untuk 1 kali produksi. Perhitungan waktu siklus diberlakukan hanya untuk alat-alat yang tidak setiap saat berproduksi secara terus menerus. Perhitungan waktu siklus berbeda untuk setiap jenis alat menurut fungsinya, yakni sebagai berikut.

\section{Excavator}

Waktu Siklus terdiri dari 4 (empat) komponen waktu, yaitu :

1. waktu muat bucket (digging time), tm;

2. waktu putar bermuatan (swing loaded time), tpb;

3. waktu buang muatan (dumping time), tb;

4. waktu putar kosong/kembali (swing empty empty time), tpk. Jadi waktu siklus atau cycle time adalah :

$$
\mathrm{Ct}=\mathrm{tm}+\mathrm{tpb}+\mathrm{tb}+\mathrm{tpk} \text { (menit) }
$$

Waktu siklus masih dipengaruhi oleh faktor kedalaman galian yaitu :

$$
\mathrm{R}=\frac{\text { kedalaman menggali }}{\text { kedalaman max galian alat }} \times 100 \%
$$

Sehingga waktu siklus diperhitungkan adalah :

$$
\mathrm{Cta}=\mathrm{Ctx} \mathrm{R} \text { (menit) }
$$

\section{Dump truck}

Untuk waktu siklus dump truck terdiri dari 5 komponen waktu yaitu :

- Waktu muat

- Waktu berangkat

- Waktu kembali ( kosong )

- Waktu pembongkaran

- Waktu antri (Sjachdirin M.etal,1998)

Jadi waktu siklus adalah :

$$
\begin{aligned}
& \mathrm{Cmt}=\mathrm{n} . \mathrm{Cms}+\frac{D}{V 1}+\mathrm{t} 1+\frac{D}{V 2}+\mathrm{t} 2 \\
& \mathrm{n}=\frac{\Phi \mathrm{l}}{q \mathrm{l}} \times \mathrm{K}
\end{aligned}
$$

Dimana :

$$
\begin{array}{ll}
\mathrm{Cmt} & =\text { Waktu siklus dump truck } \\
\mathrm{n} & =\text { Jumlah Siklus yang diperlukan excavator } \\
\mathrm{CI} & =\text { Kapasitas rata-rata dump truck }\left(\mathrm{m}^{3}\right) \\
\mathrm{qI} & =\text { Kapasitas bucket }\left(\mathrm{m}^{3}\right) \\
\mathrm{K} & =\text { Faktor bucket dari excavator } \\
\mathrm{Cms} & =\text { Waktu siklus excavator }(\text { menit }) \\
\mathrm{D} & =\text { Jarak angkut dump truck }(\mathrm{m}) \\
\mathrm{V} 1 & =\text { Kecepatan rata-rata truck bermuatan }(\mathrm{m} / \text { menit}) \\
\mathrm{V} 2 & =\text { Kecepatan rata-rata kosong }(\mathrm{m} / \text { menit }) \\
\mathrm{t} 1 & =\text { Waktu buang (menit) } \\
\mathrm{t} 2 & =\text { Waktu tunggu dan tunda (menit) }
\end{array}
$$


2. Bulldozer

Waktu siklus yang dibutuhkan untuk suatu buIldozer menyelesaikan satu siklus dapat dihitung dengan rumus berikut :

$$
\mathrm{Cm}=\frac{D}{E}+\frac{D}{R}+\mathrm{Z}(\text { menit })
$$

Dimana :

$$
\begin{array}{ll}
\mathrm{D} & =\text { jarak angkut }(\mathrm{m}) \\
\mathrm{F} & =\text { kecepatan maju (m/menit) } \\
\mathrm{R} & =\text { kecepatan mundur (m/menit) } \\
\mathrm{Z} & \text { = waktu perseneling. }
\end{array}
$$

Sedangkan perhitungan produksi persiklus bulldozer adalah :

$$
\mathrm{q}=\mathrm{I} \times \mathrm{H}^{2} \times \mathrm{a}
$$

Dimana :

$$
\begin{array}{ll}
\mathrm{Q} & =\text { produksi persiklus }\left(\mathrm{m}^{3}\right) \\
\mathrm{I} & =\text { lebar sudu/blade (meter) } \\
\mathrm{H} & =\text { tinggi sudu/blade (meter) } \\
\mathrm{a} & \text { = faktor sudu/blade }
\end{array}
$$

\section{Produktifitas Alat Berat}

langkah pertama dalam membuat estimasi kapasitas alat adalah menghitung kapasitas operasi alat-alat berat. Hasil perhitungan tersebut kemudian dibandingkan dengan pengalaman yang nyata dari pekerjaan-pekerjaan yang pernah dilakukan dari pekerjaan-pekerjaan sejenis.

\section{Produksi Excavator}

Produksi perjam dari excavator dapat dihitung dengan rumus berikut :

$$
\mathrm{Q}=\frac{q x 60 x E}{6 m}\left(\mathrm{~m}^{3} / \mathrm{jam}\right)
$$

Produksi persiklus (q) :

$$
\mathrm{q}: \mathrm{qI} \times \mathrm{K}
$$

Dimana :

$$
\begin{array}{ll}
\mathrm{Q} & =\text { produksi perjam }\left(\mathrm{m}^{3} / \mathrm{jam}\right) \\
\mathrm{q} & =\text { produksi per siklus }\left(\mathrm{m}^{3}\right) \\
\mathrm{Cm} & =\text { waktu siklus (menit) } \\
\mathrm{E} & =\text { Job faktor } \\
\mathrm{qI} & =\text { kapasitas bucket } \\
\mathrm{K} & =\text { faktor bucket }
\end{array}
$$

\section{Produksi Dump Truck}

Produksi perjam dari dump truck dapat dihitung dengan rumus berikut :

$$
\begin{aligned}
& \mathrm{P}=\frac{c x 60 x E}{c m t}\left(\mathrm{~m}^{3} / \mathrm{jam}\right) \\
& \mathrm{C}=\mathrm{n} \times \mathrm{qI} \times \mathrm{K}
\end{aligned}
$$


Dimana :

$$
\begin{array}{ll}
\mathrm{P} & =\text { produksi perjam }\left(\mathrm{m}^{3} / \mathrm{jam}\right) \\
\mathrm{C} & =\text { produksi per siklus }\left(\mathrm{m}^{3}\right) \\
\mathrm{Cmt} & =\text { waktu siklus dump truck (menit) } \\
\mathrm{E} & =\text { Job faktor } \\
\mathrm{N} & =\text { Jumlah siklus dari excavator mengisi dump truck } \\
\mathrm{qI} & =\text { kapasitas bucket } \\
\mathrm{K} & \text { = faktor bucket }
\end{array}
$$

\section{Produksi Dump Truck}

Produksi perjam dari bulldozer dapat dihitung dengan rumus berikut :

$$
\mathrm{o}=\frac{q x 60 x E}{\mathrm{~cm}}\left(\mathrm{~m}^{3} / \mathrm{jam}\right)
$$

Dimana :

$$
\begin{array}{ll}
\mathrm{Q} & =\text { produksi perjam }\left(\mathrm{m}^{3} / \mathrm{jam}\right) \\
\mathrm{q} & =\text { produksi per sikIus }\left(\mathrm{m}^{3}\right) \\
\mathrm{Cm} & =\text { waktu siklus (menit) } \\
\mathrm{E} & =\text { Job faktor }
\end{array}
$$

\section{Jumlah Kebutuhan Peralatan}

\section{Kebutuhan Excavator dan Dump Truck}

Untuk menghitung kebutuhan peralatan excavator dapat dirumuskan sebagai berikut :

$$
\mathrm{n}=\mathrm{V} /(\text { We } \times \mathrm{S} \times \mathrm{Q})
$$

Dimana :

$$
\begin{array}{ll}
\mathrm{n} & =\text { jumlah unit peralatan perjenis (unit) } \\
\mathrm{V} & =\text { volume perjenis pekerjaan }\left(\mathrm{m}^{3}\right) \\
\mathrm{We} & =\text { waktu efektif hari kerja (hari) } \\
\mathrm{S} & =\text { standar jam kerja perhari }(\mathrm{jam} / \mathrm{hari}) \\
\mathrm{Q} & =\text { produksi peraIatan }\left(\mathrm{m}^{3} / \mathrm{jam}\right)
\end{array}
$$

Untuk dump truck karena pekerjaan berseri, maka rumusan kebutuhan peralatan perseri kegiatan adalah :

$$
\begin{aligned}
& \mathrm{n} 1=\mathrm{R} \times \mathrm{n} \text { (unit) } \\
& \mathrm{n} 2=\mathrm{R} \times \mathrm{n} 1 \text { (unit) dst }
\end{aligned}
$$

dimana $\mathrm{R}$ adalah perbandingan produksi peralatan pada kegiatan seri 1 dengan produksi peralatan pada kegiatan seri 2.

$$
\begin{aligned}
& \mathrm{R}=\frac{Q}{Q_{1}} \\
& \mathrm{R} 2=\frac{Q_{1}}{Q_{2}}
\end{aligned}
$$

n, n1, n2, dst, adalah jumlah unit perjenis alat yang sesuai dengan jenis kegiatan (Ir. Susy Fatena Rostiyanti, 2002)

\section{Kebutuhan Bulldozer}

Untuk menghitung kebutuhan peralatan bulldozer dapat dirumuskan sebagai berikut : 


$$
\mathrm{n}=\mathrm{V} /(\mathrm{We} \times \mathrm{S} \times \mathrm{Q})
$$

Dimana :

$$
\begin{array}{ll}
\mathrm{n} & =\text { jumlah unit peralatan perjenis (unit) } \\
\mathrm{V} & =\text { volume perjenis pekerjaan }\left(\mathrm{m}^{3}\right) \\
\mathrm{We} & =\text { waktu efektif hari kerja }(\text { hari }) \\
\mathrm{S} & =\text { standar jam kerja perhari }(\mathrm{jam} / \mathrm{hari}) \\
\mathrm{Q} & =\text { produksi peralatan }\left(\mathrm{m}^{3} / \mathrm{jam}\right)
\end{array}
$$

\section{Biaya Operasional}

Biaya operasionaI merupakan biaya-biaya yang harus dikeluarkan agar alat dapat bekerja, berikut adalah biaya yang harus dikeluarkan:
a. bahan bakar
b. bahan pelumas mesin
c. bahan pelumas transmisi
d. minyak hidrolik
e. gemuk
f. filter-filter
g. bahan pokok
h. biaya operator
i. pemeliharaan
j. mobilisasi dan demobilisasi

\section{METODE PENELITIAN}

Iangkah-Iangkah untuk menyusun JurnaI IImiah ini disusun daIam suatu kerangka penelitian sebagai berikut :

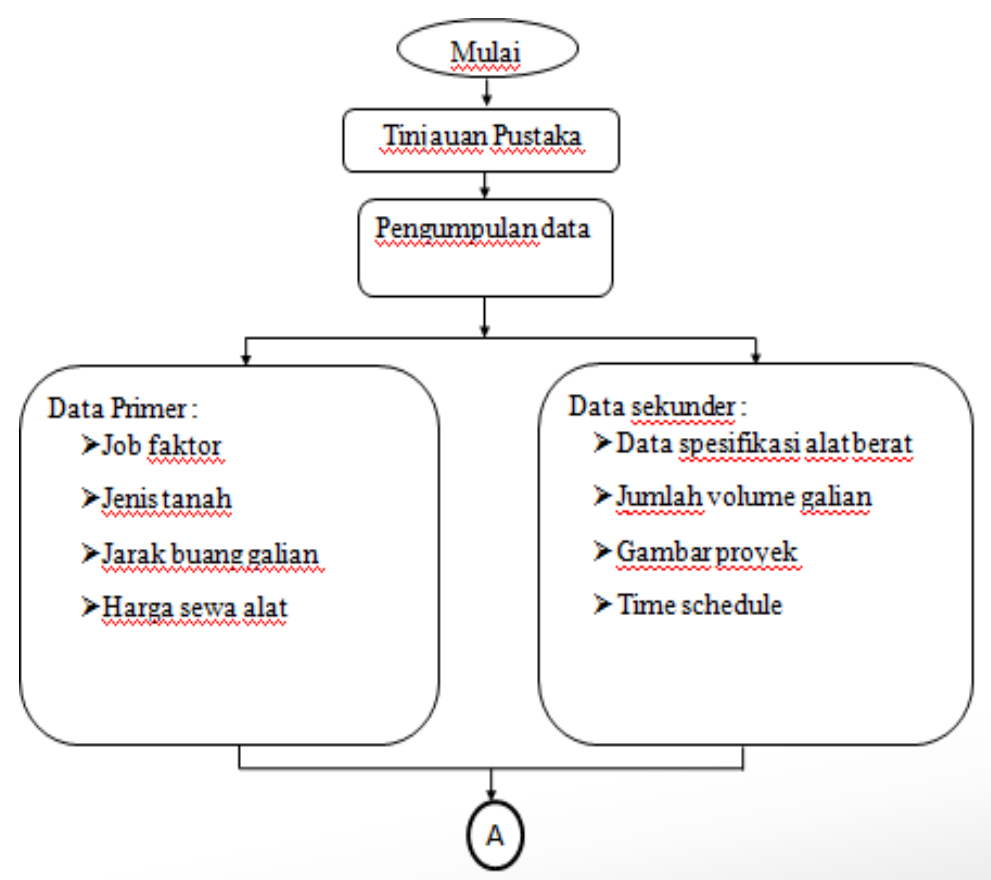




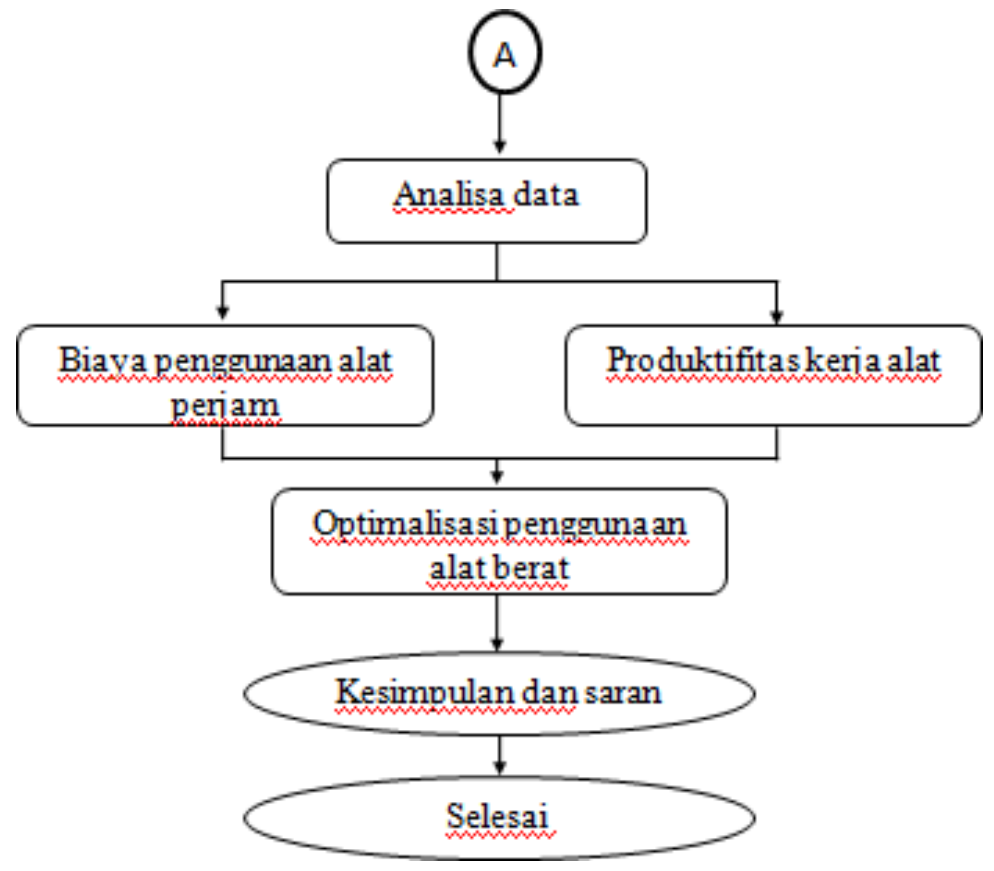

\section{PERENCANAAN DAN ANALISIS}

\section{Kondisi Lapangan}

Pada studi kasus Proyek Pembangunan Dealer Honda Pasific Kab. Tulungagung yang berlokasi di Kecamatan Kauman, Kabupaten Tulungagung, Provinsi Jawa Timur ini memiliki kreteria tanah berupa tanah lempung, selain itu Iokasi ini merupakan bekas perkebunan. Kontur tanah Iokasi pembangunan berupa tanah persawahan dengan elevasi terendah sekitar kurang lebih $70 \mathrm{~m}$ dan elevasi tertinggi sekitar kurang lebih $81 \mathrm{~m}$ dari permukaan air laut. Karena pembangunan proyek ini berfungsi sebagai tempat penyimpanan kendaraan roda empat maka diperlukan permukaan tanah yang rata dan Iuas untuk menampung kendaraan roda empat tersebut. Untuk meratakan tanah Iokasi proyek diambil elevasi $77 \mathrm{~m}$ untuk keseluruhan Iokasi yang memiliki luas sebesar $6.400 \mathrm{~m}^{2}$

\section{Jenis Tipet Alat}

Berdasarkan penjelasan diatas maka kebutuhan alat yang direncanakan adalah:

- Excavator Komatsu PC100-6, kapasitas bucket 0,5 $\mathrm{m}^{3}$

- Excavator Komatsu PC 200-8, kapasitas bucket 0,9 $\mathrm{m}^{3}$

- Excavator Hyundai R210-7H, kapasitas bucket 1,2 $\mathrm{m}^{3}$

- Dump Truck kapasitas $5 \mathrm{~m}^{3}$

- Dump Truck kapasitas $8 \mathrm{~m}^{3}$

- BuIldozer Catepillar D3G, dengan lebar blade 2,461 m dan tinggi blade 0,936 m

\section{Produktifitas Alat}

Dalam melaksanakan pekerjaan pemindahaan tanah mekanis dengan menggunakan alatalat berat, satu hal penting yang harus diperhatikan adalah mengetahui kapasitas operasi dari alat-alat berat yang digunakan. Berikut hasil perhitungan produksi dari masing-masing alat yang telah di rencanakan :

\section{Excavator}

- Produksi Excavator Komatsu PC100-6, kapasitas bucket 0,5 $\mathrm{m}^{3}=53,20 \mathrm{~m}^{3} / \mathrm{jam}$.

- Produksi Excavator Komatsu PC 200-8, kapasitas bucket $0,9 \mathrm{~m}^{3}=95,76 \mathrm{~m}^{3} / \mathrm{jam}$.

- Produksi Excavator Hyundai R210-7H, kapasitas bucket 1,2 $\mathrm{m}^{3}=114,01 \mathrm{~m}^{3} / \mathrm{jam}$. 


\section{Dump Truck}

- Produksi Dump Truck kapasitas $5 \mathrm{~m}^{3}$ yang dipasangkan dengan Excavator kapasitas bucket $0,5 \mathrm{~m}^{3}=23,51 \mathrm{~m}^{3} / \mathrm{jam}$.

- Produksi Dump Truck kapasitas $5 \mathrm{~m}^{3}$ yang dipasangkan dengan Excavator kapasitas bucket $0,9 \mathrm{~m}^{3}=30,58 \mathrm{~m}^{3} / \mathrm{jam}$.

- Produksi Dump Truck kapasitas $8 \mathrm{~m}^{3}$ yang dipasangkan dengan Excavator kapasitas bucket $0,9 \mathrm{~m}^{3}=40,52 \mathrm{~m}^{3} / \mathrm{jam}$.

- Produksi Dump Truck kapasitas $8 \mathrm{~m}^{3}$ yang dipasangkan dengan Excavator kapasitas bucket $1,2 \mathrm{~m}^{3}=43,58 \mathrm{~m}^{3} / \mathrm{jam}$.

\section{Bulldozer}

- Bulldozer Catepillar D3G = 26,92 $\mathrm{m}^{3} / \mathrm{jam}$.

\section{Kombinasi Penggunaan Alat Berat}

Setelah dilakukan perhitung jumlah kebutuhan penggunaan alat berat, maka dibuatkan 4 buah Kombinasi alat yang ditentukan berdasarkan produktifitas dari masing-masing alat tersebut. Berikut 4 kombinasi yang direncanakan:

\section{- Kombinasi I :}

1 unit excavator berkapasitas $0,5 \mathrm{~m}^{3}$

3 unit dump truck berkapasitas $5 \mathrm{~m}^{3}$

2 unit bulldozer D3G

- Kombinasi II :

1 unit excavator berkapasitas $0,9 \mathrm{~m}^{3}$

4 unit dump truck berkapasitas $5 \mathrm{~m}^{3}$

3 unit bulldozer D3G

\section{- Kombinasi III :}

1 unit excavator berkapasitas $0,9 \mathrm{~m}$

3 unit dump truck berkapasitas $8 \mathrm{~m}^{3}$

3 unit bulldozer D3G

\section{- Kombinasi IV :}

1 unit excavator berkapasitas $1,2 \mathrm{~m}^{3}$

3 unit dump truck berkapasitas $8 \mathrm{~m}^{3}$

3 unit bulldozer D3G

\section{Penjadwalan Penggunaan Alat Berat}

Penjadawalan dibuat agar kita dapat mengetahui kapan alat mulai bekerja dan berapa Iama alat tersebut bekerja. Untuk menghitung waktu Iama alat bekerja dapat menggunakan rumus sebagai berikut :

$$
\text { Waktu pengerjaan }=\frac{\text { volume tanah }}{\text { produktivitas alat } x \text { jam kerja }}
$$

Dari hasil perhitungan maka diperoleh waktu pengerjaan untuk semua alat yaitu :

\section{- Kombinasi I}

1 unit excavator $0,5 \mathrm{~m}^{3}$ dengan waktu 72 hari

3 unit dump truck $5 \mathrm{~m}^{3}$ dengan waktu 72 hari

2 unit bulldozer D3G dengan waktu 71 hari

\section{- Kombinasi II}

1 unit excavator $0,9 \mathrm{~m}^{3}$ dengan waktu 40 hari

4 unit dump truck $5 \mathrm{~m}^{3}$ dengan waktu 40 hari 
3 unit bulldozer D3G dengan waktu 48 hari

\section{- Kombinasi III}

1 unit excavator $0,9 \mathrm{~m}^{3}$ dengan waktu 40 hari

3 unit dump truck $8 \mathrm{~m}^{3}$ dengan waktu 40 hari

3 unit buIldozer D3G dengan waktu 48 hari

\section{- Kombinasi IV}

1 unit excavator $1,2 \mathrm{~m}^{3}$ dengan waktu 34 hari

3 unit dump truck $8 \mathrm{~m}^{3}$ dengan waktu 34 hari

3 unit bulldozer D3G dengan waktu 48 hari

\section{Biaya Sewa Alat}

Biaya sewa alat adalah biaya yang harus dibayar oleh pihak penyewa alat kepada pemilik alat. Biaya sewa terdiri dari biaya sewa alat perjam, biaya operator, biaya bahan bakar, biaya mobilisasi dan demobilisasi. Berikut adalah hasil perhitungan biaya sewa alat pada setiap kombinasi:

- Kombinasi I : Rp. 808.740.000,-

- Kombinasi II : Rp. 600.920.000,-

- Kombinasi III: Rp. 594.920.000,-

- Kombinasi IV: Rp. 560.960.000,-

\section{Pemilihan Penggunaan Alat Berat}

Setelah dilakukan perhitungan dari masing masing-masing kombinasi alat yang telah di rencanakan sebelumnya, diperoleh waktu yang dibutuhkan oleh alat berat untuk mengerjakan pekerjaan galian tanah dan biaya dari setiap kombinasi. Dari TabeI 4.8 dapat dilihat penggunaan alat berat pada kombinasi IV Iebih optimal dan tepat dalam pekerjaan galian tanah pada proyek pembangunan Dealer Honda Pasific karena memiliki biaya pelaksanaan sewa alat yang lebih rendah di banding dengan kombinasi alat yang Iainnya. Selain itu kombinasi IV memiliki waktu pengerjaan yang lebih singkat dari time schedule yang telah direncanakan sebelumnya.

TabeI. 1 Waktu dan Biaya Pekerjaan Galian Tanah

\begin{tabular}{|c|c|c|c|}
\hline Kombinasi & Alat yang digunakas & $\begin{array}{c}\text { Wakita } \\
\text { pekerjaan }\end{array}$ & Total Biaya \\
\hline \multirow{3}{*}{1} & -1 unit excavatos $0,5 \mathrm{~m}^{3}$ & 72 hart & \multirow{3}{*}{ Rp. 808.740 .000 , } \\
\hline & .3 tait dump truck $5 \mathrm{~m}^{5}$ & 72 hari & \\
\hline & -2 unit bulldozer D3G & 71 hari & \\
\hline \multirow{3}{*}{ II } & -1 unit excavater $0,9 \mathrm{~m}^{\mathrm{j}}$ & 40 hari & \multirow{3}{*}{ Rp. 000920.000 . } \\
\hline & -4 unit dimp truck $5 \mathrm{~m}^{3}$ & 40 hani & \\
\hline & -3 unit bellidozet D3G & 48 hari & \\
\hline \multirow{3}{*}{ III } & -1 unit excavatoc $0,9 \mathrm{~m}^{3}$ & 40 hari & \multirow{3}{*}{ Rp. $594,920,000$, } \\
\hline & .3 thit dump truck $8 \mathrm{~m}^{3}$ & $40 \mathrm{han}$ & \\
\hline & - 3 unit bulldozer D3G & 48 hari & \\
\hline \multirow{3}{*}{ IV } & -1 unit excavanor $1,2 \mathrm{~m}^{3}$ & 34 hasi & \multirow{3}{*}{ Rp. 560.960 .000 , } \\
\hline & - 3 tunit dump truck $8 \mathrm{~m}^{3}$ & 34 hari & \\
\hline & -3 unt bulldozer D3G & 48 hart & \\
\hline
\end{tabular}




\section{KESIMPULAN DAN SARAN}

\section{Kesimpulan} bahwa:

Berdasarkan hasil analisis yang dilakukan dalam studi kasus ini menunjukkan

1. Dengan menghitung produktifitas masing- masing alat, maka diperoleh kombinasi IV berada pada peringkat pertama dengan menggunakan 1 unit excavator $1,2 \mathrm{~m}^{3}, 3$ unit dump truck berkapasitas $8 \mathrm{~m}^{3}$ dan 3 unit bulldozer D3G dengan waktu pengerjaan yang diperlukan adalah 34 hari untuk penggunaan excavator dan dump truck, sedangkan untuk penggunaan bulldozer diperlukan waktu pengerjaan selama 48 hari. Setelah itu kombianasi III berada pada peringkat ke dua dengan menggunakan 1 unit excavator $0,9 \mathrm{~m}^{3}, 3$ unit dump truck berkapasitas $8 \mathrm{~m}^{3}$ dan 3 unit bulldozer D3G dengan waktu pengerjaan yang diperlukan adalah 40 hari untuk penggunaan excavator dan dump truck, sedangkan untuk penggunaan bulldozer diperlukan waktu pengerjaan selama 48 hari. Kemudian Kombinasi II berada pada peringkat ketiga dengan menggunakan 1 unit excavator $0,9 \mathrm{~m}^{3}, 4$ unit dump truck berkapasitas $5 \mathrm{~m}^{3}$ dan 3 unit bulldozer D3G dengan waktu pengerjaan yang diperlukan adalah 40 hari untuk penggunaan excavator dan dump truck, sedangkan untuk penggunaan bulldozer diperlukan waktu pengerjaan selama 48 hari. Dan dilanjutkan dengan kombinasi I berada pada peringkat ke empat dengan menggunakan 1 unit excavator $0,5 \mathrm{~m}^{3}, 3$ unit dump truck berkapasitas $5 \mathrm{~m}^{3}$ dan 2 unit bulldozer D3G dengan waktu pengerjaan yang diperlukan adalah 72 hari untuk penggunaan excavator dan dump truck, sedangkan untuk penggunaan bulldozer diperlukan waktu pengerjaan selama 71 hari.

2. Dari hasil perhitungan biaya penggunaan alat maka diperoleh biaya yang harus dikeluarkan untuk setiap kombinasi diatas adalah sebagai berikut, kombinasi IV dengan total biaya sebesar Rp.560.960.000,- kombinasi III dengan total biaya sebesar Rp.594.920.000,- kombinasi II dengan total biaya sebesar Rp.600.920.000,- dan kombinasi I dengan total biaya yang dikeluarkan sebesar Rp.808.740.000,-. Pada pihak kontraktor kombinasi yang digunakan adalah kombinasi II dimana biaya yang dikeluarkan lebih besar dan waktu pengerjaannya lebih lama dibandingkan dengan penggunaan alat pada kombinasi IV.

\section{Saran}

Berdasarkan dari penelitian dan pengerjaan jurnal ilmiah ini, kami dapat memberikan saran-saran sebagai berikut :

1. Bagi pihak kontraktor disarankan menggunakan kombinasi IV sebagai kombinasi alat berat yang digunakan pada pekerjaan galian dan timbunan tanah di proyek tersebut. Yaitu dengan menggunakan 1 unit excavator berkapasitasa $1,2 \mathrm{~m}^{3}$ yang dipasangkan dengan 3 unit dump truck berkapasitas $8 \mathrm{~m}^{3}$ dan 3 unit bulldozer D3G. Dimana dengan kombinasi alat ini pihak kontraktor dapat meminimalisir pengeluaran biaya sewa alat.

2. Untuk memperoleh hasil yang maksimal dalam penggunaan alat berat khususnya pada pekerjaan galian tanah pihak kontraktor perlu memperhatikan kombinasi antara kapasitas bucket excavator dan kapasitas dari dump truck itu sendiri agar menghasilkan produktifitas alat secara maksimal. 


\section{DAFTAR PUSTAKA}

Departemen Pekerjaan Umum. 1998. Pedoman Perhitungan Harga Satuan Pekerjaan Dengan Menggunakan Peralatan. Penerbit Pekerjaan Umum, Jakarta.

Rochmanhadi. 1985. Perhitungan Biaya Pelaksanaan Pekerjaan dengan Menggunakan Alat-alat Berat. Penerbit Departemen Pekerjaan Umum, Jakarta.

Rochmanhadi. 1992. Alat-Alat Berat dan Penggunaannya. Penerbit Departemen Pekerjaan Umum, Jakarta.

Rostiyanti, S.F. 2002. Alat Berat Untuk Proyek Konstruksi. Penerbit Rineka Cipta, Jakarta. www.mascus.co.uk/construction/used-hammers---breakers/npk-gh3-Ioader-backhoehydbreaker/vhporcnh.htmI .

Diakses tanggaI 3/01/2015 www.twentywheeIs.com/view/130313_caterpiIlar_318cIn_cab heat air_crawler_excavator_backhoe_diesel_cat_machine_ac.htmI.

Diakses tanggal 3/01/2015 www.hargahino.com/?DUMP_TRUCK 